\title{
Chemical changes in organic matter after fungal colonization in a nitrogen fertilized and unfertilized Norway spruce forest
}

\author{
César Nicolás • Juan P. Almeida • Magnus Ellström • Adam Bahr • \\ Sharon E. Bone • Nicholas P. Rosenstock • John R. Bargar • \\ Anders Tunlid • Per Persson • Håkan Wallander
}

Received: 7 March 2017 / Accepted: 22 June 2017 / Published online: 8 July 2017

(C) The Author(s) 2017. This article is an open access publication

\begin{abstract}
Background and aims Decomposition and transformation of organic matter (OM) in forest soils are conducted by the concomitant action of saprotrophic and mycorrhizal fungi. Here, we examine chemical changes in $\mathrm{OM}$ after fungal colonization in nitrogen fertilized and unfertilized soils from a Norway spruce forest.

Methods Sand-filled bags amended with composted maize leaves were placed in the forest soil and harvested after 17 months. Infrared and near edge X-ray absorption fine structure spectroscopies were used to study the
\end{abstract}

Responsible Editor: Ingrid Koegel-Knabner.

Electronic supplementary material The online version of this article (doi:10.1007/s11104-017-3324-8) contains supplementary material, which is available to authorized users.

C. Nicolás · J. P. Almeida · M. Ellström · A. Bahr •

N. P. Rosenstock $\cdot$ A. Tunlid $\cdot$ H. Wallander

Microbial Ecology Group, Department of Biology, Lund

University, Lund, Sweden

C. Nicolás $(\triangle)$

Department of Biology, Ecology Building, Lund University, SE

22362 Lund, Sweden

e-mail: cesar_nicolas.cuevas@biol.lu.se

S. E. Bone · J. R. Bargar

Chemistry and Catalysis Division, Stanford Synchrotron

Radiation Lightsource, SLAC National Accelerator Laboratory,

Menlo Park, CA, USA

N. P. Rosenstock · P. Persson

Centre for Environmental and Climate Research, Lund University, Lund, Sweden chemical changes in the OM. Fungal community composition of the bags was also evaluated.

Results The proportion of ectomycorrhizal fungi declined in the fertilized plots, but the overall fungal community composition was similar between $\mathrm{N}$ treatments. Decomposition of the $\mathrm{OM}$ was, independently of the $\mathrm{N}$ level or soil horizon, accompanied by an increase of $\mathrm{C} / \mathrm{N}$ ratio of the mesh-bag content. Moreover, the proportions of carboxylic compounds in the incubated OM increased in the mineral horizon, while heterocyclic-N compounds decreased, especially in unfertilized plots with higher $\mathrm{N}$ demand from the trees.

Conclusions Our results indicate that more oxidized organic $\mathrm{C}$ and less heterocyclic-N proportions in the $\mathrm{OM}$ remain after fungal colonization in the mineral layers, and suggest that ectomycorrhizal fungi transfer less heterocyclic- $\mathrm{N}$ from the mesh bags to the host trees under high $\mathrm{N}$ levels.

Keywords Fungal community composition - Infrared spectroscopy · Near-edge X-ray absorption fine structure (NEXAFS) spectroscopy · Nitrogen fertilization .

Norway spruce forest $\cdot$ Organic matter decomposition

\section{Introduction}

Saprotrophic fungi are one of the major decomposers of organic matter (OM) in boreal and northern temperate forests. These microorganisms harbour a wide range of hydrolytic and oxidative enzymes such as cellobiohydrolases, laccases, peroxidases or lytic 
polysaccharide mono-oxygenases that allow them to break down plant litter (Baldrian 2006; Bugg et al. 2011; Hemsworth et al. 2013; Kohler et al. 2015) and use it as a $\mathrm{C}$ source. In addition to saprotrophic fungi, ectomycorrhizal (ECM) fungi constitute another major microbial group in boreal and northern temperate forests and may play an important role in OM decomposition. Unlike saprotrophs, ECM fungi forage the SOM to obtain nutrients such as $\mathrm{N}$ and $\mathrm{P}$ for the host plant and receive in return plant photosynthate $\mathrm{C}$. Nevertheless, the ability of ECM fungi to produce oxidative enzymes suggests a potential role for these microbes in the decomposition of soil OM (Bödeker et al. 2014; Phillips et al. 2014). Furthermore, recent studies have shown that ECM fungi have retained similar oxidative capacity as saprotrophic fungi (Shah et al. 2016). This oxidative capacity has been suggested to primarily assist the ECM fungi to mobilizing nutrients from soil OM such as $\mathrm{N}$ embedded in the soil organic complexes, rather than to obtain C from the soil OM (Lindahl and Tunlid 2015; Shah et al. 2016). However, decomposition and chemical changes of OM after ECM colonization are still poorly understood.

Fungal community composition is altered by $\mathrm{N}$ fertilization (Morrison et al. 2016). Nitrophylic fungal species more adapted to high $\mathrm{N}$ levels can proliferate in $\mathrm{N}$ fertilized soils and the diversity of saprotrophs, such as ascomycetes, which are more capable of degrading cellulose, is enhanced under $\mathrm{N}$ fertilization (Morrison et al. 2016). In addition, $\mathrm{N}$ fertilization reduces fungal biomass (Frey et al. 2014; Bahr et al. 2015), and lowers oxidase and hydrolytic activities (Allison et al. 2008; Rinkes et al. 2016). These changes in fungal composition and activity may be reflected in the chemical composition of OM. For instance, a lower fungal biomass can result into a reduced contribution of the fungal derived products (e.g. chitin and melanin from necromass, secreted enzymes) to the soil OM. Likewise, lower oxidative and proteolytic activity of saprotrophic and ECM fungi when easily available N such as ammonium forms are present, may reduce the decomposition of lignocellulosic and organic N compounds. Despite the important role of fungi in decomposition of OM in forest soils, there is still a lack of knowledge regarding how fungal colonization will affect the chemical composition of OM.

Spectroscopic methods are useful tools to study the composition of soil OM (Kögel-Knabner 2000; Lehmann et al. 2009). In this study, we combine the use of infrared spectroscopy and X-ray absorption spectroscopy to characterize the changes in the soil OM taking place after fungal colonization of $\mathrm{OM}$ added to fertilized and unfertilized forest plots. Infrared spectroscopy yields information about the chemical groups in soil $\mathrm{OM}$ and provides a fingerprint of the composition of the $\mathrm{OM}$ (Bouskill et al. 2016). Synchrotron-based near-edge Xray absorption fine structure (NEXAFS) spectroscopy is used to determine the chemical environment of $\mathrm{C}$ and $\mathrm{N}$ in the soil samples (Solomon et al. 2012; Leinweber et al. 2013; Gillespie et al. 2015). In comparison with other techniques such as infrared or nuclear magnetic resonance (NMR) spectroscopies, NEXAFS spectroscopy is very sensitive to element speciation and has been applied to soil samples in order to elucidate chemical changes in $\mathrm{C}$ and $\mathrm{N}$ of soil $\mathrm{OM}$ due to effects of land management (Solomon et al. 2005), $\mathrm{N}$ fertilization (Gillespie et al. 2013) or climate change (Purton et al. 2015).

The aim of this study was to examine changes in the chemical composition of OM after fungal colonization in fertilized and unfertilized forest soils. OM in the form of maize compost was added to sand-filled mesh bags that prevented in-growth of roots. Since maize is a C4 plant, its use as organic material allowed for quantifying the amount of new carbon (C3-carbon) that entered the mesh bags during incubation in the soil (Wallander et al. 2011). The mesh bags were placed along the soil profile from the organic to the mineral horizon to capture fungal communities from these horizons (Lindahl et al. 2007). Fungal colonization and community composition in the mesh bags were assessed at the end of the soil incubation period. The first hypothesis of the study was that there would be an increase of the $\mathrm{C} / \mathrm{N}$ ratio of the organic material of the mesh bags due to a preferential removal of $\mathrm{N}$ by the ECM fungi. Furthermore, we expected this effect to be larger in the unfertilized plots where the demand for $\mathrm{N}$ is higher. Our second hypothesis was that the proportion of organic $\mathrm{N}$ pools would change during incubation since ECM fungi were expected to transfer some organic $\mathrm{N}$ pools to the plant host, while other pools would accumulate as residues of fungal necromass.

\section{Materials and methods}

Site and experimental design

The experiment was conducted at Tönnersjöheden research park $\left(56^{\circ} 41^{\prime} \mathrm{N}, 13^{\circ} 5^{\prime} \mathrm{E}\right)$ in the county of Halland, 
Southwestern Sweden. The annual precipitation is 800 $1050 \mathrm{~mm}$ and the average temperature ranges between $6.1-7.3^{\circ} \mathrm{C}$. The soil type is a Haplic Podzol according to IUSS Working Group WRB (2006), and its texture is sandy. The experimental site was afforested with Norway spruce (Picea abies) and established in 1979.

A total of six plots $(30-40 \mathrm{~m}$ by $25 \mathrm{~m}$ ) were selected for the experiment: three of these were amended with $200 \mathrm{~kg} \mathrm{~N} \mathrm{ha}^{-1}$ in the form of $\mathrm{NH}_{4} \mathrm{NO}_{3}$ in July 2011, and three were used as control. At the same time, cylindrical mesh bags (length $16 \mathrm{~cm}$ and diameter $2 \mathrm{~cm}$ ) filled with $70 \mathrm{~g}$ acid-washed quartz sand $(0.36-2.00 \mathrm{~mm}, 99.6 \%$ $\mathrm{SiO}_{2}$, Ahlsell AB, Malmö, Sweden) and 2\% dry weight composted maize materials were placed in the experimental plots. The compost material was produced by composting chopped maize leaves for 12 months in an isolated compost bin placed outside. After composting, the material was stored at $4{ }^{\circ} \mathrm{C}$ until use in the experiment. The use of composted maize leaves was selected as organic material in order to estimate the amount of fungal $\mathrm{C}$ entering the mesh bags from the surrounding soil. This was done by analyzing the change in the $\delta^{13} \mathrm{C}$ in the compost material originated from maize leaves (C4 plant) when colonized by fungi from the soil (C originated from C3 plants) (Wallander et al. 2011). A total of six mesh bags per plot were vertically installed along the soil profile from the humus horizon to the mineral horizon. The depth of the humus horizon at each site was recorded. The mesh size of the bags $(50 \mu \mathrm{m})$ allowed fungal hyphae to penetrate the bags but excluded the roots, and enabled the estimation of the accumulation of ectomycorrhizal biomass in the mesh bags (Wallander et al. 2001). The bags were collected in November 2012, and the contents of the bags were divided into two groups. One corresponded to the humus horizon at the site where the bags were placed, and the other corresponded to the upper mineral soil. The bags were subsequently stored at $-20^{\circ} \mathrm{C}$ until chemical or biological analysis. The contents of all mesh bags from a given soil horizon in a single plot were pooled and mixed to obtain one sample for each soil horizon per plot.

Analysis of the fungal colonization and community composition in the mesh bags

Fungal colonization in the mesh bags was estimated using three different methods: scoring, counting and ergosterol measurement. The scoring method consisted of visual estimation of the extramatrical mycelium with a stereomicroscope using a 6-graded scale (Wallander et al. 2001). The counting method examined the frequency of hyphae present in mesh-bag holes along vertical rows in increments of 100 mesh holes. The ergosterol method consisted of the extraction and quantification of the fungal-specific membrane lipid ergosterol via high-performance liquid chromatography coupled with a UV detector (Bahr et al. 2015).

The fungal community composition in mesh bags and the initial maize material was characterized after DNA extraction, amplification, sequencing and analysis of the fungal DNA. The DNA was extracted from $5 \mathrm{~g}$ of homogenized ground material from each composite sample obtained from six mesh bags with a CTAB buffer ( $2 \%$ cetyltrimethylammonium bromide, $2 \mathrm{mM}$ EDTA, and $150 \mathrm{mMTris}-\mathrm{HCl}, \mathrm{pH} 8$ ) and incubated at $65^{\circ} \mathrm{C}$ for $1.5 \mathrm{~h}$, followed by chloroform centrifugation and isopropanol/ethanol precipitation, and purification with Nucleo-spin DNA clean up kit (Machery-Nagel, Düren, Germany). Three technical replicates were performed for each sample for extraction, PCR, and sequencing.. Negative controls were used for the extraction and amplification steps and consisted of $3 \mathrm{ml}$ MilliQ water instead of $5 \mathrm{~g}$ mesh bag contents.

The ITS2 region was amplified using fungal-specific primers ITS7g (Ihrmark et al. 2012) and ITS4 (Gardes and Bruns 1993). The ITS2 region and these primers exhibit low bias for high-throughput sequencing studies due to lower length variation of the amplicon and reduced primer bias (Ihrmark et al. 2012). The forward and reverse primers contained adapters used to attach the barcodes in the next steps. Each $25 \mu$ l of PCR reaction consisted of $0.25 \mu$ l Phusion polymerase ${ }^{\circledR}$ (Thermo Scientific, Waltham, MA, USA), $5 \mu$ Buffer $5 \mathrm{X}, 0.5 \mu \mathrm{l}$ dNTPs $(10 \mathrm{mM}), 1.5 \mu \mathrm{l}$ ITS7g $(10 \mu \mathrm{M})$, $1.5 \mu \mathrm{lTS} 4(10 \mu \mathrm{M}), 1 \mu \mathrm{l} \mathrm{BSA}(20 \mathrm{mg} / \mathrm{ml})$, and $1.5 \mu \mathrm{l}$ of template DNA $(5 \mathrm{ng} / \mu \mathrm{l})$. After PCR (initial denaturation at $98^{\circ} \mathrm{C}$ for $30 \mathrm{~s}$; then 31 cycles of $98^{\circ} \mathrm{C}$ for $10 \mathrm{~s}$, $56^{\circ} \mathrm{C}$ for $30 \mathrm{~s}$, and $72{ }^{\circ} \mathrm{C}$ for $30 \mathrm{~s}$, with a final extension for $8 \mathrm{~min}$ at $72{ }^{\circ} \mathrm{C}$ ), the products were subjected to AMPure ${ }^{\circledR}$ purification (AgencourtAMPure XP, Beckman Coulter, Brea, CA, USA) to remove primers, dNTPs, short fragments, and sequencing inhibitors. A second 8-cycle amplification was then performed to attach Nextera sample-specific barcodes (Illumina Inc., San Diego, CA, USA) for sorting after sequencing. Following the Nextera amplification, PCR products were subjected to an additional AMPure $\AA_{\text {purification, }}$ 
and the purified PCR products were measured using a Quant-iT ${ }^{\mathrm{TM}}$ PicoGreen ${ }^{\circledR}$ dsDNA Assay Kit (Invitrogen ${ }^{\mathrm{TM}}$, Carlsbad, CA, USA). Equal amounts of DNA from each sample were then pooled and submitted for Illumina sequencing with paired end (325 bp forward; 275 bp reverse) sequencing on MiSeqsequenator using the MiSeq Reagent Kit v3 chemistry (Illumina Inc., San Diego, CA, USA). Negative extraction and PCR controls yielded no detectable DNA. All sequences were submitted to the International Nucleotide Sequence Database Sequence Read Archive (accession no. SRR3591717).

The sequences were trimmed and filtered using Mothur v1.34 (Schloss et al. 2009). Sequences outside the ITS2 region and chimeric sequences were removed using ITSx extractor v1.5.0 (Bengtsson-Palme et al. 2013). After filtering, the sequences were clustered using the Gaussian Mixture model CROP (Hao et al. 2011) at 97\% sequence similarity, and a set of operational taxonomic units (OTUs) were thus obtained. The taxonomic identity was then assigned to the set of clustered sequences by searching the Full "UNITE + INSD" dataset (Kõljalg et al. 2013) using the Basic Local Alignment Tool (BLASTN program 2.2.25, blast.ncbi.nlm.nih.gov). Sequences that presented a $96 \%$ similarity between the query sequence and top hit, with at least $80 \%$ coverage of the query sequence length, were assigned to a taxonomic identity with genus and species. Sequences with values of $94-95 \%$ similarity between the query sequence and top hit were considered to be assigned a taxonomic identity at the genus level only.

All OTUs which represented less than 10 total reads and occurring in only one sample were removed from the OTU abundance matrix and read abundances within each OTU were averaged between the technical replicates for each sample. Rarefaction was performed to the median number of reads across all samples, 17,345 reads. Read abundances for all OTUs for each sample were then summed and expressed as the relative abundance per sample, such that total abundance for each sample was 1 . This rarefied relative abundance matrix containing the abundance of OTUs per sample was used to analyze the community composition differences. The total fungal community was divided by ecological function (ECM fungi, saprotrophic fungi, plant pathogens and unknown ECM fungi); OTUs were considered to be known ECM fungi based on the most current knowledge of the ecology of known close relatives (genera or species) according to Tedersoo et al. (2010). The assignment of the remaining OTUs was done to the best of our knowledge. For data visualization, only OTUs with greater than 50 reads were shown (representing $>99 \%$ of the total reads).

Chemical analysis of the organic matter in the mesh bags

Total organic $\mathrm{C}$ and total $\mathrm{N}$ contents of the samples from the mesh bags, as well as from the initial maize material that had not been incubated in the soil, were measured using a TOC analyzer equipped with a TNM-1 detector (Shimadzu). The $\mathrm{pH}$ of the incubated mesh bags was measured in a 1:5 dilution of mesh-bag content: water. Nitrate and ammonium of the initial mesh-bag content were determined by flow injection analysis (FIAstar 5000, Foss, Denmark) on an extract obtained after shaking the material for $2 \mathrm{~h}$ with a $2 \mathrm{M} \mathrm{KCl}$ solution $(1: 20, w / v)$.

In order to estimate the import of $\mathrm{C}$ to the mesh bags, the ${ }^{13} \mathrm{C}$ in the samples was analyzed (Wallander et al. 2011). The determination of the natural abundance of ${ }^{13} \mathrm{C}$ in the samples from the mesh bags and from the initial maize material was performed with an isotope ratio mass spectrometer (Isoprime, Manchester, UK). The isotopic composition of the samples was expressed as deviations relative to standard reference materials:

$\delta^{13} C(\% o)=\left(\frac{R_{\text {sample }}-R_{\text {standard }}}{R_{\text {standard }}}\right) * 1000$

where $\mathrm{R}$ is the molar ratio of ${ }^{13} \mathrm{C} /{ }^{12} \mathrm{C}$. The standard reference material for $\mathrm{C}$ was the Vienna Pee Dee Belemnite limestone. The proportion of new $\mathrm{C}$ in the mesh bags was calculated with a two component mixing model:

$C_{4}-$ carbon $=\left(\frac{\delta^{13} C_{\text {sample }}-\delta^{13} C_{\text {new carbon }}}{\delta^{13} C_{4}-\delta^{13} C_{\text {new carbon }}}\right)$

where the values of $\delta^{13} \mathrm{C}_{\text {new carbon }}$ were obtained from extracted mycelia from mesh bags with sand from a similar forest $(-25.82 \% \circ \pm 0.02, n=2)$, and the value $\delta^{13} \mathrm{C}_{4}$ was determined from the initial maize compost $(-13.36 \%$ o $\pm 0.02, n=3)$.

Fourier Transform Infrared (FTIR) spectra were recorded using a Bruker Tensor 27 (Bruker Scientific Instruments, Billerica, MA, USA). The data were collected in diffuse reflectance mode on freeze-dried dissolved OM mixed with potassium bromide (2:100, $\mathrm{m} / \mathrm{m}$ ). The dissolved OM was obtained by extracting 
the mesh bag content using distilled water $(1: 5, \mathrm{~m} / \mathrm{v})$ for $24 \mathrm{~h}$ under agitation. The solution was then filtered through $0.22 \mu \mathrm{m}$ and freeze-dried. Each spectrum was the result of 128 consecutive scans at a resolution of $4 \mathrm{~cm}^{-1}$. Six vibrational modes of the spectra were mainly used to identify changes of the functional groups in the OM: C-O and C-O-C stretching of carbohydrates $\left(970-1150 \mathrm{~cm}^{-1}\right)$ and $\mathrm{C}-\mathrm{O}$ stretching of phenolics (1150-1250 $\mathrm{cm}^{-1}$ ), N-O stretching of nitrates or N-H bending of ammonium (1380-1400 $\left.\mathrm{cm}^{-1}\right)$, O-H bending and aliphatic C-H deformation $\left(1350-1450 \mathrm{~cm}^{-1}\right)$, $\mathrm{C}-\mathrm{C}$ stretching of aromatic rings $\left(1510 \mathrm{~cm}^{-1}\right)$ and $\mathrm{C}=\mathrm{O}$ stretching of carbonyl groups $\left(1620-1800 \mathrm{~cm}^{-1}\right)$.

NEXAFS spectra were collected at the beamline 11ID-1 (SGM) of the Canadian Light Source facilities in Saskatoon, Canada. The organic material from the mesh bags, as well as the initial maize material, was ground and slurried in water $(1: 160, w / v)$. An aliquot of $50 \mu \mathrm{l}$ of the samples were deposited on $5 \times 5 \mathrm{~mm}^{2}$ indium foil (Sigma Aldrich), which had previously been cleaned with acetone and ethanol, and the sample was allowed to dry on a hot plate at $30^{\circ} \mathrm{C}$ in a laminar flow cabinet. This process was repeated six times. The indium foil was fixed to NEXAFS sample holders using double-sided carbon tape. The measurements were performed in fluorescence mode and each scan was collected from fresh, unexposed locations on the sample. The spectra were recorded using a slew scanning mode at the C K-edge (275-320 eV) and the N K-edge (390$430 \mathrm{eV}$ ) in order to minimize the X-ray exposure, and a minimum of 8 scans were collected per sample. The beam spot size was $1000 \times 100 \mu \mathrm{m}^{2}$ and the beamline exit slit was 25 . The energy resolution of the measurement $(E / \Delta E)$ was higher than 5000 . For calibrations of the $\mathrm{C}$ and $\mathrm{N}$ K-edges, the absorption spectra for citric acid and ammonium sulfate were measured, respectively. Normalization of N K-edge spectra was done by using the beamline flux $\left(\mathrm{I}_{0}\right)$ using an in-line gold mesh, while that of $\mathrm{C} \mathrm{K}$-edge spectra was done by measuring the $I_{0}$ on a freshly gold-sputtered film located at the sample chamber. Additionally, all spectra were normalized to an edge jump equal to 1 .

Spectral deconvolution was done by using Gaussian curves and error functions with the program 'fityk version 0.9.8' (Wojdyr 2010) (Fig. S1). Initially, error functions were fitted to the edge jumps and then a series of Gaussian curves were centered according to the energy position of $\mathrm{C}$ and $\mathrm{N}$ species found in literature. Thus, Gaussian curves were set at 284.3, 285.3, 286.0,
286.6, 287.4, 288.4 and $289.3 \mathrm{eV}$ in the NEXAFS C1s spectra corresponding to quinone-C, substituted aromatic-C, aromatic-C/pyridinic-C, phenolic-C, aliphatic-C, carboxyl-C and O-alkyl-C, respectively (Solomon et al. 2009; Gillespie et al. 2014; Purton et al. 2015). Gaussian curves for the N K-edge were placed at 398.8, 400, 401.4, 402.7 and $405.4 \mathrm{eV}$ corresponding to heterocyclic-N (e.g. pyrimidine, pyridine), nitrilic/ heterocylic-N, amidic-N, pyrrolic-N and nitrate-N/ammonium-N, respectively (Leinweber et al. 2007, 2010). In addition, Gaussian curves before the edge were set to equal a full width at the maximum height of $1.2 \mathrm{eV}$, while those after the edge were not constrained before iteration. The relative abundances of the $\pi^{*}$ transitions were finally determined with respect to the sum of all $\pi^{*}$ transitions and were used as indicators of the content of major $\mathrm{C}$ and $\mathrm{N}$ types in the samples.

\section{Statistical analysis}

All statistical analysis regarding fungal community composition was conducted using the VEGAN R package (Oksanen et al. 2016). Differences in fungal community composition between samples were calculated with Bray-Curtis dissimilarity and plotted in non-metric multidimensional scaling ordination plots (NMDS). The statistical significance of the differences in community composition was tested using permutation multivariate analysis of variances (PERMANOVA).

One-way ANOVA was used for the statistical analysis of fungal biomass and chemical parameters between, and a post-hoc Tukey's honestly significant difference (HSD) test, was applied to establish differences between treatments. The Welch and Brown-Forsythe tests were applied to establish differences between groups in case of unequal variances. A two-tailed test of population mean with unknown variances was used when $\mathrm{N}$ types obtained from NEXAFS spectroscopy were compared with the initial material. The statistical comparison between horizons was not conducted, because both samples were not strictly independent. Principal component analysis (PCA) was performed on both the relative abundance of the peak area obtained from NEXAFS spectroscopy and the infrared spectral data. Infrared spectral data had previously been normalized to the same total area before PCA analysis. SPSS 13.0 software (IBM, USA) and R version 3.1.2 (R Development Core Team 2014) were used for data analysis. 


\section{Results}

Fungal colonization and community in the mesh bags in the organic and mineral horizon

Fungal colonization measured using the different methods (ergosterol, counts and score) tended to be lower in the mesh bags placed in fertilized plots at both soil horizons, although there were no significant differences among treatments (Fig. 1a, b).

We obtained 814,942 sequence reads from sequencing and had 721,849 reads after quality filtering. Initial clustering resulted in 2257 OTUs. After taxonomic assignment, eliminating rare taxa $(<10$ reads) and taxa that only occurred in one sample and averaging of technical replicates we had 298 OTUs corresponding to 255,252 reads with a range of 13,810 to 24,843 reads per sample (Fig. S2a). Approximately $4 \%$ of the reads could not be assigned a taxonomic identity. Of those for which a taxonomic identity could be assigned, ecological role was inferred to $99.6 \%$ of the OTUs, which accounted for ECM fungi, saprotrophs and plants pathogens (Fig. 2). Compared to the initial compost material, the material incubated in the mesh bags at the organic and mineral horizons contained a significant proportion of ECM, which ranged from $30.6-43.5 \%$. $\mathrm{N}$ fertilization was associated with a $10 \%$ lower ECM fungal abundance in the mesh bags at the humus and mineral horizons relative to the control $(p<0.05$ and $p=0.06$, respectively) (Fig. 2). In total, $59 \mathrm{ECM}$ fungal species were identified ( 26 species if the abundance cut-off was more than 50 reads), with the most abundant being similar in the fertilized and control plots (Fig. 2, Fig. S2b, Fig. S3).

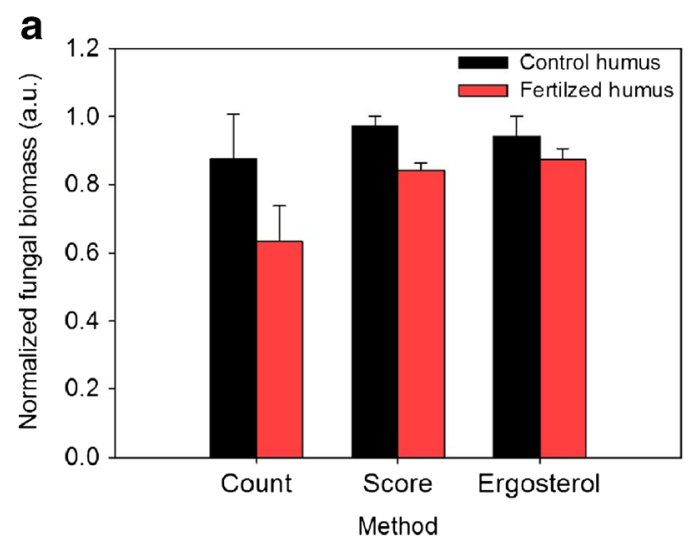

Fig. 1 Normalized fungal colonization obtained from the mesh bags of the control (blue bars) and fertilized plots (red bars) after 17 months of incubation (a) in the organic and (b) in the mineral
The ECM fungi included Tylospora fibrillosa and Tylospora asterophora, which represented $67-85 \%$ of the total ECM species, followed by Amanita sp., Wilcoxina sp. and Lactarius tabidus. Nitrogen fertilization did not produce a significant change in ECM community composition as revealed by PERMANOVA analysis for the organic horizon $\left(\mathrm{R}^{2}=0.18, p=0.9\right)$ or the mineral horizon $\left(\mathrm{R}^{2}=0.18, p=0.6\right)$ (Fig. 3a, b).

Regarding the saprotrophic fungi, their fungal abundance ranged from 49.6-63.8\% with respect to the total fungal abundance. A number of fungal species that were not present in the initial material (maize compost), proliferated in the mesh bags under field conditions and represented an average of $12 \%$ of the total fungal abundance. This was the case for saprotrophic Cryptosporiopsis sp., which was not present in the initial material and comprised $7 \%$ of the total fungal abundance after the bags were incubated in the field (Fig. 2). Moreover, in the mineral horizon, the abundance of this particular OTU in the mesh bags placed in the fertilized soils was $80 \%$ lower than those in the control soils $(p<0.05)$. Similarly, the abundance of the saprotrophic fungus Myceliophthora heterothallica was significantly higher in the fertilized soils of the mineral horizon $(p<0.05)$. The number of species in the mesh bags was similar in the control and fertilized plots at both horizons (Fig. S4).

When the total fungal communities, including all OTUs were compared, $\mathrm{N}$ fertilization did not result in any differences in the fungal community of the mesh bags in the organic horizon $\left(\mathrm{R}^{2}=0.24, p=0.3\right)$ or in the mineral horizon $\left(\mathrm{R}^{2}=0.37, p=0.1\right)$ (Fig. 3c, d).

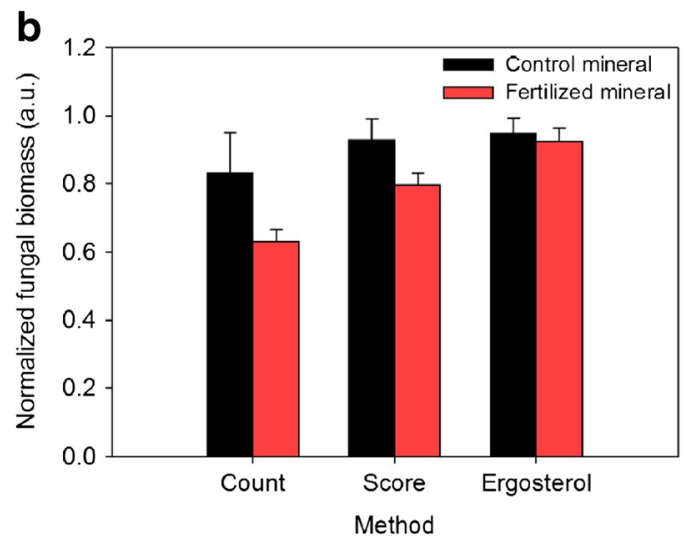

horizon determined by counting, scoring and ergosterol methods (error bars are standard errors, $n=3$ ). Values are normalized to the maximum value of each method 


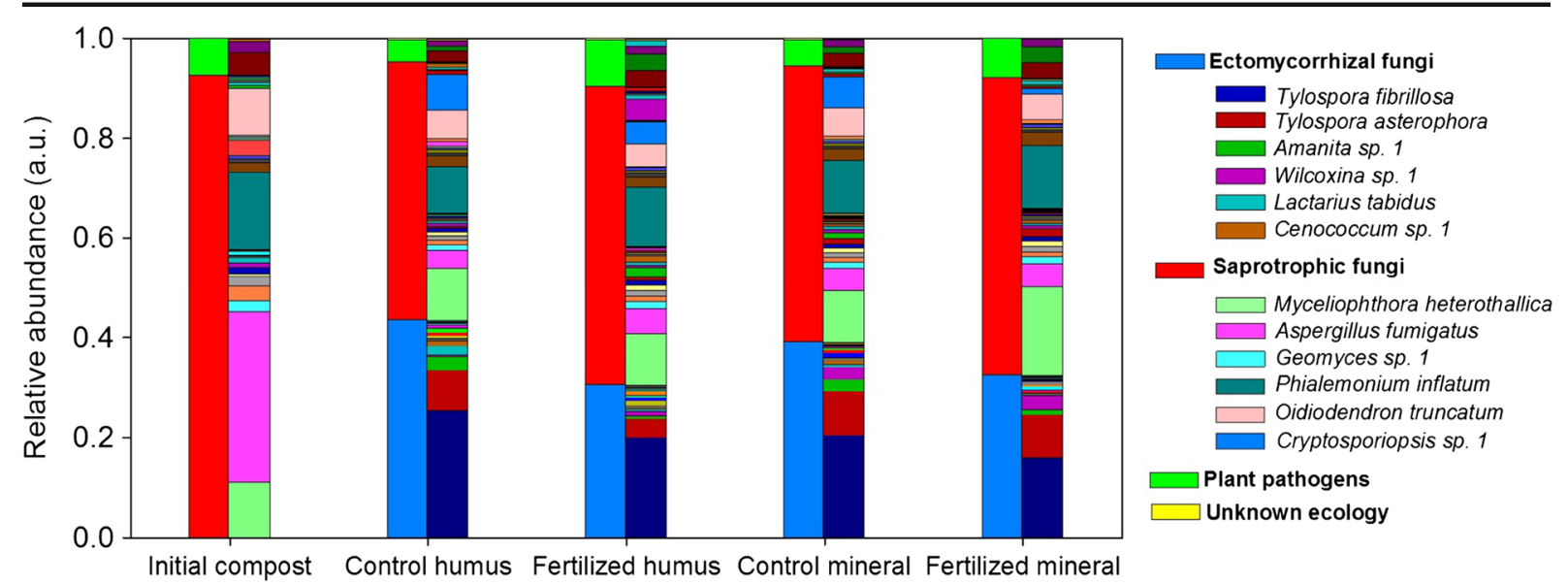

Fig. 2 Relative abundance of fungal OTUs obtained from the mesh bags of the control and fertilized plots at the beginning of the experiment (initial material) and after 17 months of incubation in the organic and in the mineral horizon. The relative abundance was normalized to the number of reads. For each sample, the left stacked bar shows the fungal OTUs grouped according to their ecological role, and the right stacked bar shows all fungal OTUs, where a selected number of the most abundant OTUs ( 12 out of 83 OTUs) are indicated in the legend. Each bar represent the mean abundance of three replicates, except for the initial material that had one replicate. Only OTUs with greater than 50 sequence reads (representing $99 \%$ of the total sequence reads) are depicted. The list of ectomycorrhizal and saprotrophic fungi are shown in Fig. S3-S4
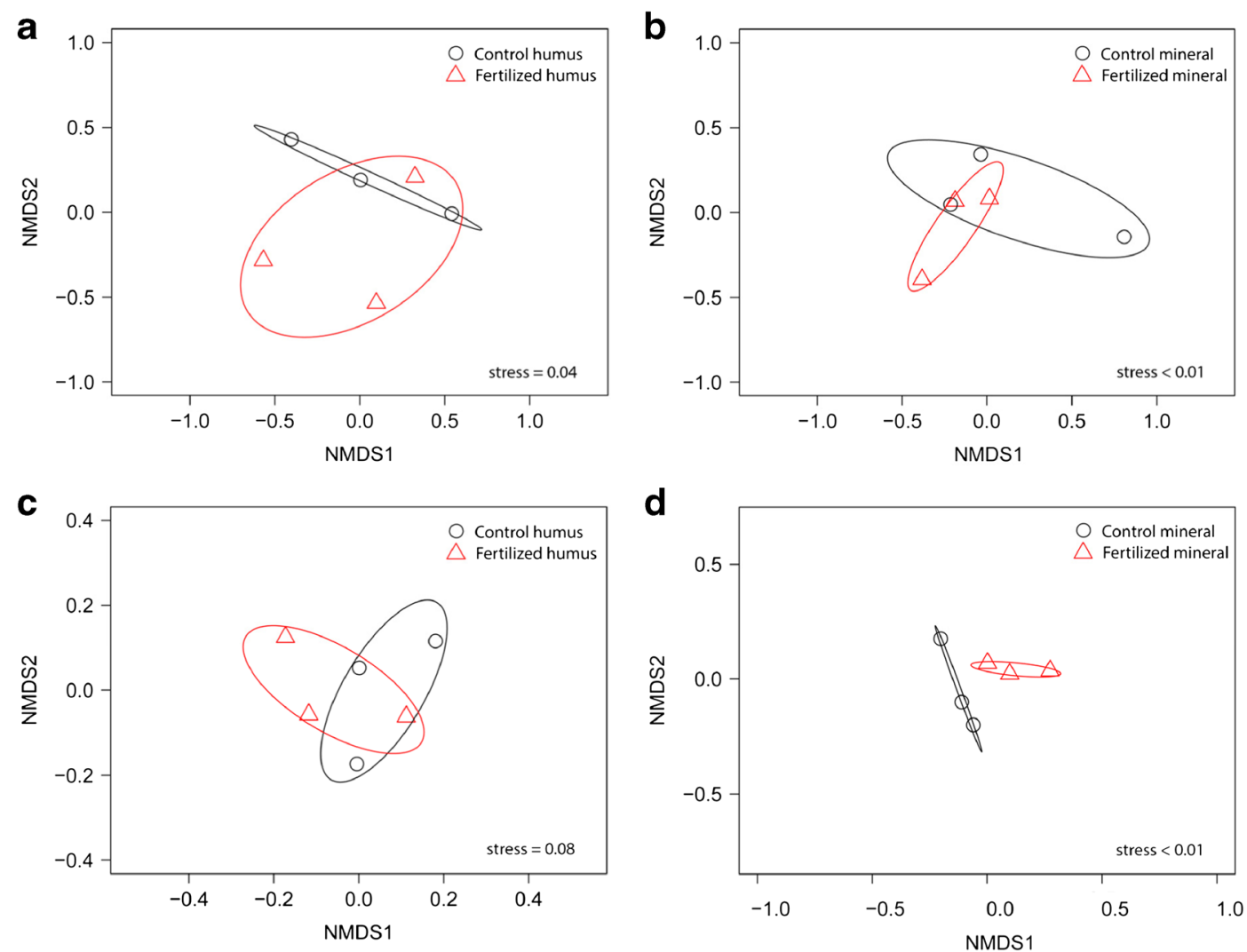

Fig. 3 Non-metric multidimensional scaling (NMDS) ordination of ectomycorrhizal fungal OTUs (a, b) and all fungal OTUs (c, d) obtained from the mesh bags of the control and fertilized plots

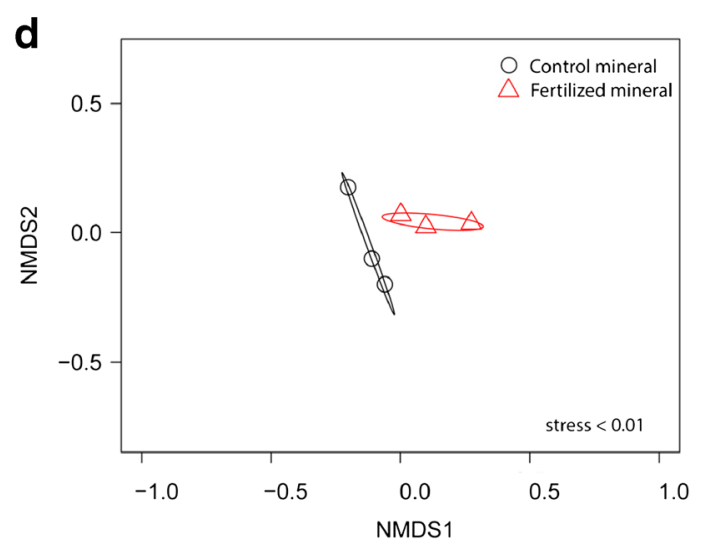

placed in the organic and in the mineral horizon $(n=3)$. Ellipses represent a 95\% confidence interval around the mean for the different treatments 
Chemical analysis of the organic matter in the mesh bags in the organic and mineral horizons

Mesh bags from the organic horizon showed similar amounts of $\mathrm{C}$ and $\mathrm{N}$ compared to the initial material, while a significant decrease for both $\mathrm{C}$ and $\mathrm{N}$ in the mineral horizon was observed ( $p<0.05$, Table 1$)$. Input of carbon from outside the mesh bags (from C3 plant such as Norway spruce) that resulted in a decrease of ${ }^{13} \mathrm{C}$ in the mesh bag content occurred at both horizons with respect to initial material. No significant changes in the isotopic composition $\left({ }^{13} \mathrm{C}\right)$ or the $\mathrm{pH}$ of the mesh bags were found between control and fertilized treatments (Table 1). Estimation of the $\mathrm{C}$ input in the mesh bags ranged from 0.82 to $0.86 \mathrm{mg} \mathrm{C} \mathrm{g}^{-1}$ sand, which corresponded to a $10 \%$ of the total $\mathrm{C}$. However, there were no differences between the control and fertilized plots at both horizons. Nitrogen fertilization did not result in changes in the $\mathrm{C}$ and $\mathrm{N}$ content of the mesh bags, and the mesh bags placed in control plots showed similar values to those in the fertilized plots in both soil horizons. The $\mathrm{C} / \mathrm{N}$ ratios of the mesh bags increased significantly in comparison to that of the initial material (on average $21 \%$ more with respect to the $\mathrm{C} / \mathrm{N}$ ratio of the initial material). The $\mathrm{C} / \mathrm{N}$ ratios tended to be higher in control plots than in fertilized ones, although this difference was not statistically significant. Since the ECM biomass in these forests has a $\mathrm{C} / \mathrm{N}$ ratio of 20 (Wallander et al. 2003) and taking into account that new $C$ in the mesh bags was $10 \%$, the contribution of fungal biomass to the total increase of $\mathrm{C} / \mathrm{N}$ was estimated to be $32 \%$.
Likewise, the initial amount of nitrates and ammonium in the mesh bags were 0.03 and $0.002 \mathrm{~g} \mathrm{~kg}^{-1}$, respectively. This corresponded to 3 and $0.2 \%$ of nitrates and ammonium with respect to total $\mathrm{N}$, respectively. Thus, considering this inorganic $\mathrm{N}$ as initially leached out, their contribution to the total increase of $\mathrm{C} / \mathrm{N}$ was estimated of $16 \%$.

Infrared spectra of the initial material were characterized by a dominant sharp peak, which is ascribed to nitrates and ammonium (peak at $1380 \mathrm{~cm}^{-1}$ ). This peak disappeared when the mesh bags were incubated in the field (Fig. S4). In addition, a peak in the initial material at $1170 \mathrm{~cm}^{-1}$ also disappeared at the end of the experiment. When compared the infrared spectra of mesh bags incubated in the field, PCA separated the organic matter in fertilized plots from the control plots in both horizons, with the differences in the mineral horizon being significant along principal component 2 (PC2) (Fig. 4b) $(p<0.05)$. PC2 accounted for $31.3 \%$ of the total variance and was mainly related to four vibrational regions: carbohydrate stretching, at $1100 \mathrm{~cm}^{-1}$; aliphatic deformation, at $1350-1450 \mathrm{~cm}^{-1}$; aromatic skeletal vibration, at $1510 \mathrm{~cm}^{-1}$; and carbonyl region, at 1620 $1850 \mathrm{~cm}^{-1}$ (Fig. 4b). The PC2 loading plots revealed that this separation was based on higher content of carbohydrates in the control samples, while the fertilized ones seemed to be characterized by aromatic skeletal vibration and carbonyl groups (Fig. 4d).

As decomposition occurred more intensively in the mineral horizon (Table 1), the material of the mesh bags of this horizon was further investigated. Near edge Xray absorption fine structure (NEXAFS) spectroscopy

Table 1 Chemical characteristics and carbon decay constant rates of the mesh bag contents at the beginning of the experiment (initial material) and after 17 months of incubation in the humus and mineral layers of the control and fertilized plots at the Norway spruce forest

\begin{tabular}{|c|c|c|c|c|c|}
\hline & \multirow[t]{2}{*}{ Initial material $^{\mathrm{a}}$} & \multicolumn{2}{|l|}{ Humus layer } & \multicolumn{2}{|l|}{ Mineral layer } \\
\hline & & Control & Fertilized & Control & Fertilized \\
\hline $\mathrm{C}\left(\mathrm{g} \mathrm{kg}^{-1}\right)$ & $12.1(1.4) \mathrm{a}$ & $10.3(0.4) \mathrm{a}$ & $10.0(0.8) \mathrm{a}$ & $8.1(0.4) b$ & $8.6(0.1) b$ \\
\hline $\mathrm{N}\left(\mathrm{g} \mathrm{kg}^{-1}\right)$ & $1.02(0.11) \mathrm{a}$ & $0.71(0.05) \mathrm{a}$ & $0.70(0.04) \mathrm{a}$ & $0.55(0.02) b$ & $0.62(0.07) b$ \\
\hline $\mathrm{C} / \mathrm{N}$ & $11.9(0.1) \mathrm{a}$ & $14.7(0.5) b$ & $14.3(0.3) b$ & $14.8(0.6) b$ & $14.0(0.1) b$ \\
\hline$\Delta 13 \mathrm{C}(\% \circ)$ & $-13.36(0.3) \mathrm{a}$ & $-15.6(0.2) b$ & $-15.1(0.2) b$ & $-15.0(0.2) b$ & $-15.2(0.2) b$ \\
\hline $\mathrm{pH}$ & ND & $4.16(0.02)$ & $4.28(0.03)$ & $4.25(0.09)$ & $4.19(0.03)$ \\
\hline $\mathrm{C}$ decay constant rates $\left(\mathrm{yr}^{-1}\right)^{\mathrm{b}}$ & & $0.11(0.02)$ & $0.14(0.04)$ & $0.29(0.03)$ & $0.25(0.06)$ \\
\hline
\end{tabular}

${ }^{\text {a }}$ Standard error is in parentheses $(n=3)$. Values followed by different lowercase letters indicate significant difference between treatments and the initial material $(p<0.05)$

${ }^{\mathrm{b}}$ Calculated assuming one-compartmental exponential model, $\mathrm{C}_{\text {final }}=\mathrm{C}_{\text {initial }} * \mathrm{e}^{-\mathrm{kt}}$ 

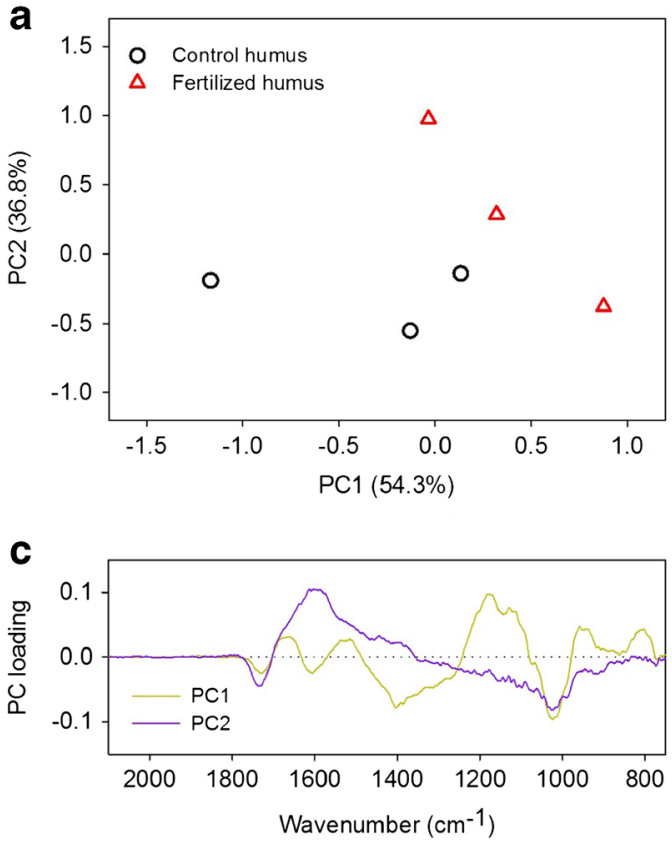

Fig. 4 PCA scores (a, b) and loadings plot (c, d) of the infrared spectra of the dissolved organic matter obtained from the mesh bags after 17 months of incubation in the organic (on the left side)

was applied to the samples of this horizon. The carbon K-edge spectra were similar for both control and fertilized treatments (Fig. 5a), as also indicated by the relative abundances estimated from the deconvoluted peaks (Table S1) and the fact that the treatments were grouped together in the PCA plot (Fig. 5b). However, weak trends were observed in the peak ascribed to carboxyl$\mathrm{C}$, which displayed higher intensity and relative abundance in the field samples as compared to the initial material, while the peak attributed to aromatic- $\mathrm{C}$ decreased (Fig. 5b, Table S1).

Regarding the $\mathrm{N}$ compounds, all samples showed predominance of amidic-N. The peaks at $398.8 \mathrm{eV}$ and $400 \mathrm{eV}$, attributed to heterocyclic- $\mathrm{N}$ and nitrilic/ heterocylic-N, were significantly lower in the incubated material in comparison to the initial material, with the control showing the lowest values (Fig. 5c, Table S1). PCA plots also revealed that field samples enriched in organic $\mathrm{N}$ such as amidic- and pyrrolic-N, while the abundance of heterocyclic-N (e.g. pyridine) and nitrilic-N diminished (Fig. 5d). A prominent peak at $405.4 \mathrm{eV}$, attributed to nitrate-N/ammonium-N, dominated the spectra of the initial material, but this was absent in the NEXAFS spectra of the mesh bags after 17 months (Fig. 5c).
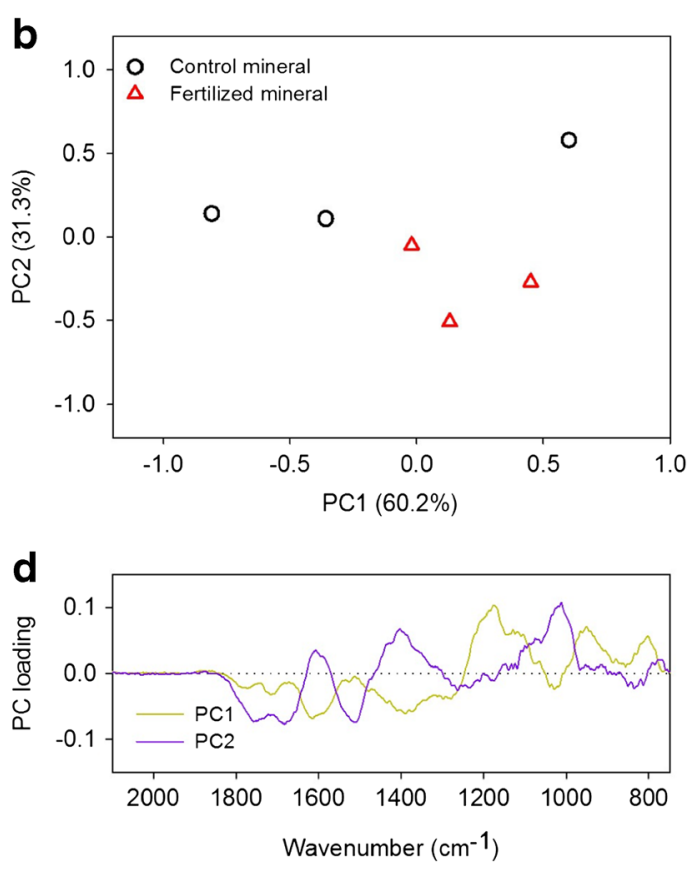

and mineral horizons (on the right side) of control and fertilized plots at the Norway spruce forest $(n=3)$

\section{Discussion}

Fungal colonization and community composition of the mesh bags

Colonization of sand-filled mesh bags is usually dominated by ECM fungi, although a lesser amount of saprotrophic fungi is also present (Wallander et al. 2001, 2010). Wallander et al. (2010) found on average $70 \%$ ECM fungi in similar mesh bags without OM amendment in the same experimental site. However, the addition of compost in the present study resulted in a higher proportion of saprophytic fungi, and ECM fungi constituted 30$43 \%$ of the fungal abundance. Saprophytic fungi in the mesh bags were dominated by fungi originally present in the compost with $43 \%$ of the fungal reads, and only $12 \%$ corresponded to new colonizing saprotrophic fungi such as Crystoporiopsis spp. In contrast to our results, other studies have shown that the soil microbial community displaces the compost-borne microbial community of organic amendments applied to soil (Saison et al. 2006). It is likely that keeping the material confined in the mesh bags has prevented the displacement of the compost-borne community. Other researchers have used gammaradiation to sterilize the $\mathrm{OM}$ added to the mesh bags and 

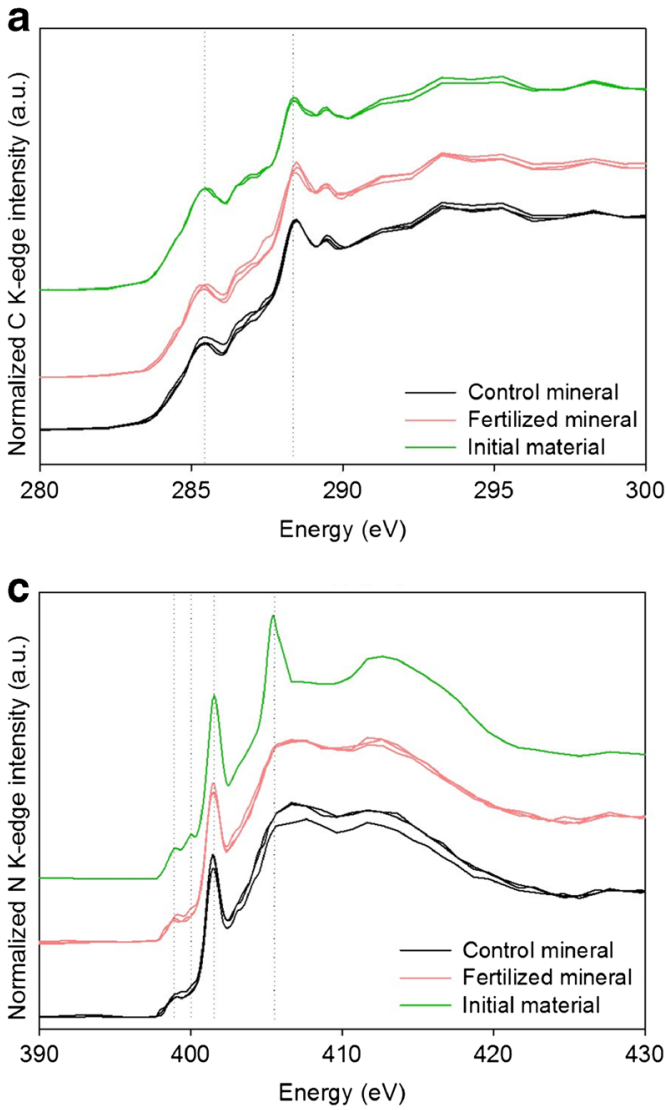

Fig. 5 NEXAFS C1s (a) and N1s K-edge spectra of the organic matter (c), and the corresponding PCA scores and loading plot of their deconvoluted peak areas $(\mathbf{b}, \mathbf{d})$, obtained from the mesh bags at the beginning of the experiment (initial material) and after 17 months of incubation in the mineral horizon of the control and fertilized plots. Vertical dotted lines in the $\mathrm{C} 1 \mathrm{~s} \mathrm{~K}$-edge spectra indicate aromatic-C, at $285.3 \mathrm{eV}$, and carboxyl-C, at $288.4 \mathrm{eV}$ ( $n=2$ for the initial material, and $n=3$ for the material inside the

obtained community composition with ECM and saprotrophic fungal abundances of $70 \%$ and less than 9\% relative to the total fungal abundance, respectively (Phillips et al. 2014). Nevertheless, it is important to bear in mind that the compost-borne fungi, which were present in mesh bags at both horizons and treatments, may or may not be adapted to the new conditions imposed in the environment. For instance, the saprotrophic fungi Myceliophthora heterothallica and Aspergillus fumigatus are compost-borne fungi that grow well under thermophilic conditions (Mehta and Satyanarayana 2013), but they would not be expected to grow at the low temperatures of the studied forest soils. In addition, some portion of these sequence reads likely arose from DNA extracted from dormant spores rather than active
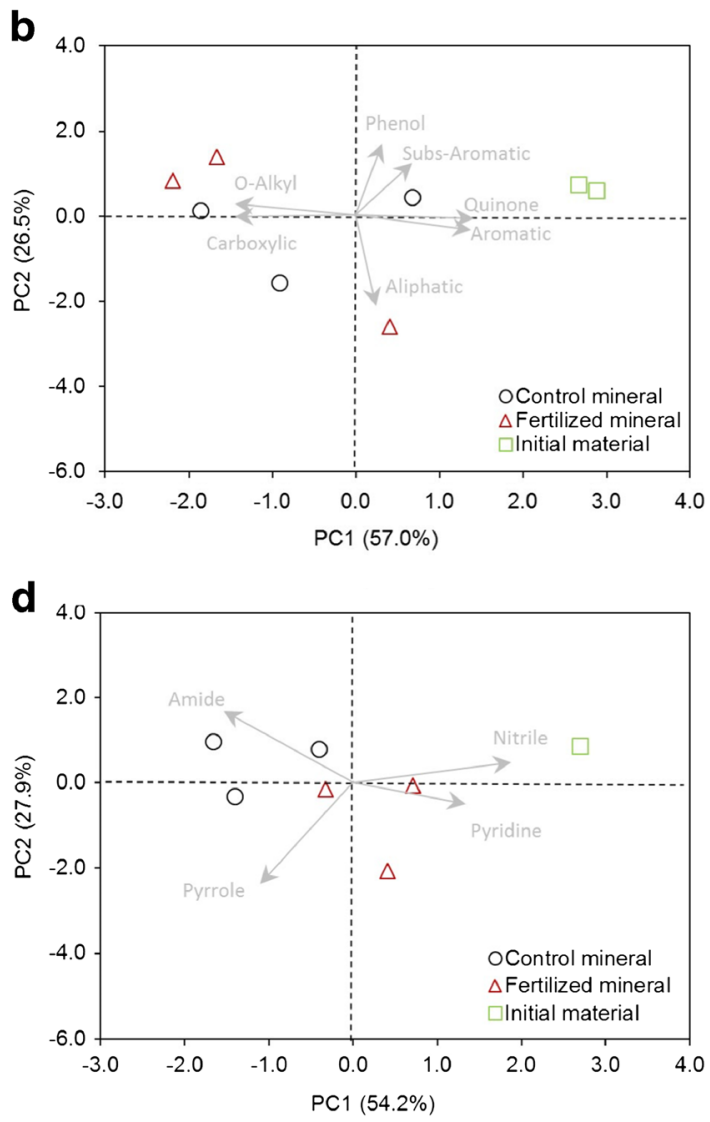

mesh bags). For N1s K-edge spectra, vertical dotted lines indicate heterocyclic-N (pyridine), at $398.8 \mathrm{eV}$; nitriles and aromatic- $\mathrm{N}$, at $400 \mathrm{eV}$; amidic-N, at $401.4 \mathrm{eV}$; and nitrate-N, at $405.4 \mathrm{eV}(n=1$ for the initial material, and $n=3$ for the material inside the mesh bags). Spectra are pre-edge baseline corrected and post-edge normalized to 1 . Loading factors were multiplied by 3 to improve visualization

hyphae. Therefore, the high OTU abundances of some of these saprotrophic fungi may not be indicative of their decomposition activity.

Although a change in the fungal community structure at different $\mathrm{N}$ levels has been observed (Kjøller et al. 2012; Morrison et al. 2016), the fungal community, neither the total fungal community nor the ECM fungal community, did not change under $\mathrm{N}$ fertilization. It has been observed that the microbial community composition tends to be more significantly affected by mineral fertilization when the application is prolonged in time (Geisseler and Scow 2014), although there has also been found no effects on ECM fungal community composition if fertilization is balanced in nutrients (Hay et al. 2015). The similar fungal community composition 
between treatments in our 17-month experiment therefore points to the fact that more frequent fertilization and longer time studies are needed to obtain significant changes in the fungal community structure.

Chemical changes in the organic matter of the mesh bags after fungal colonization

In partial agreement with our first hypothesis, the decomposition of OM in the mesh bags was, independently of the $\mathrm{N}$ treatment or soil horizon, accompanied by an increase of $\mathrm{C} / \mathrm{N}$ ratio of the organic material. It seems that there was a demand for $\mathrm{N}$, even in fertilized plots, and earlier studies have suggested that the Norway spruce forest in this experimental site is $\mathrm{N}$ limited (Bahr et al. 2015). The decrease in the organic $\mathrm{C}$ was likely due to the fungal and bacterial saprotrophic degradation, while the increase of the $\mathrm{C} / \mathrm{N}$ ratio in the organic material could be due to the transfer of $\mathrm{N}$ to the plant by ECM fungi. A similar increase in $\mathrm{C} / \mathrm{N}$ ratios was also observed in soil horizons from coniferous forests dominated by ECM fungi and was attributed to a preferential uptake and transfer of $\mathrm{N}$ by the ECM fungi (Lindahl et al. 2007). Nevertheless, the increase of the $\mathrm{C} / \mathrm{N}$ ratio in our experiment was not exclusively due to $\mathrm{N}$ transfer by ECM fungi and almost half of this increase was due to the contribution of fungal biomass and inorganic $\mathrm{N}$ leaching in the mesh bags. It seems thereby that fungal colonization underwent with a concomitant action of saprotrophs and ectomycorrhizal fungi, which exploited the nutrient resources and modified the chemical composition of the OM supplied in the mesh bags. The role of bacteria in the decomposition of the organic matter inside the mesh bags cannot also be overseen, since they can constitute more than half of the microbial biomass in coniferous forest soils (Hartmann et al. 2012). Although the bacterial community composition is less affected by $\mathrm{N}$ addition (Freedman et al. 2015), bacteria may also have contributed to the decomposition of organic matter. However, it is unlikely that bacterial activity has contributed to the increase in $\mathrm{C} / \mathrm{N}$ ratio of the $\mathrm{OM}$ since they cannot transport $\mathrm{N}$ over long distances.

Oxidative reactions are used by saprotrophic and ECM fungi in order to get access to nutrients in the OM (Martínez et al. 2011; Shah et al. 2016). These oxidative reactions include side chain oxidations, which can lead to an increase of carboxyl-C in the OM. The diminution of the abundance of substituted aromatic $\mathrm{C}$ and an increase of more oxidized compounds such as carboxyl-C in the mineral horizon may then indicate that oxidative mechanisms were likely occurring inside the mesh bags. There was also a stronger OM decomposition of the mesh bags in the mineral layer in comparison to the organic horizon, probably due to their different abiotic conditions. Environmental conditions such as moisture content affect the microbial activity and can be different between layers (Söderström 1979). For instance, the upper layer of the soil in these forests tends to dry out during summer, which could have resulted in lower activity leading to a lower decomposition rate in comparison to that of the mineral horizon.

Changes in the organic $\mathrm{N}$ pool of the mesh bags after fungal colonization

Regarding our second hypothesis, there was a change in the proportion of organic $\mathrm{N}$ compounds in the mesh bags. The relative abundance of heterocyclic- $\mathrm{N}$ within the mesh bags decreased after fungal colonization, especially in the unfertilized plots. This modification in the relative abundance of organic $\mathrm{N}$ compounds was not mainly produced by the increase of fungal biomass in the mesh bags, since isotopic analysis and ergosterol measurements showed a similar fungal biomass between fertilized and unfertilized plots. There was then likely occurring a preferential use of the heterocyclic-N compounds by the fungi present in the mesh bags. It is known that fungi prefer taking up forms of $\mathrm{N}$ such as ammonium or glutamine if available, but fungi can also use, when such $\mathrm{N}$ forms are not available, other $\mathrm{N}$ sources such as nitrates, amines, amides, purines and pyrimidines (Marzluf 1997). Amidic-N is usually the dominant organic $\mathrm{N}$ source (up to $50 \%$ in many soils), but the fraction corresponding to heterocyclic- $\mathrm{N}$, originated from nucleotide bases, chlorophyll or carbohydrates, can account up to $13-35 \%$ of the total organic $\mathrm{N}$ in the soil (Schulten and Schnitzer 1997; Talbot and Treseder 2010). Therefore, heterocyclic-N seems to be an important $\mathrm{N}$ source that fungi do not neglect under field conditions. Our results, however, do not exclude the fact that ECM fungi have simultaneously used other organic $\mathrm{N}$ sources such as amidic-N.

The larger ECM fungal abundance and lower heterocyclic-N relative abundance in the unfertilized plots compared to the fertilized plots, together with their trends of higher enrichment of $\mathrm{C} / \mathrm{N}$ ratio, suggest a possible role of ECM fungi in utilizing and transporting the organic- $\mathrm{N}$, especially the heterocyclic-N, to the host tree. Some ECM fungi have the capacity to use heterocyclic-N (Talbot and Treseder 
2010), although there is still little known about its use by ECM fungi in forest soils. Among ECM fungi found in the mesh bags, the most abundant ectomycorrhizal fungal species, Tylospora fibrillosa, tended to decrease after $\mathrm{N}$ fertilization. T. fibrillosa has the capacity to use organic $\mathrm{N}$ sources such as the insoluble plant protein gliadin (Taylor et al. 2000), and has also been found to express manganesedependent peroxidase activity, which could have given access to $\mathrm{N}$ sources associated to polyphenols (Chambers et al. 1999). Nevertheless, decomposition of $\mathrm{OM}$ by saprotrophic microorganisms (bacteria and fungi) might also have facilitated the access to these organic $\mathrm{N}$ forms for ECM fungi as suggested by other authors (Wu 2011).

\section{Conclusion}

Fungal colonization of the organic material in the mesh bags resulted in chemical changes in the OM composition and was accompanied by an increase of $\mathrm{C} / \mathrm{N}$ ratio of the mesh-bag content. The large abundance of ECM fungi in the mesh bags suggests that the depletion in $\mathrm{N}$ of OM during decomposition was due to the transfer of $\mathrm{N}$ by ECM fungi to the plant. Moreover, the use of novel spectroscopic techniques such as NEXAFS spectroscopy revealed that the relative abundance of heterocyclic$\mathrm{N}$ diminished in the mesh bags from the mineral horizon of unfertilized plots in comparison to those of the initial material and fertilized ones. T. fibrillosa was the most abundant ECM species colonizing the mesh bags and may have contributed to the decline in heterocyclic-N. Further experiments under controlled conditions are needed to understand the importance of heterocyclic-N as $\mathrm{N}$ source for fungal community, especially for ECM fungi.

Acknowledgments C.N. thanks the Knut and Alice Wallenberg Foundation for its financial support. The NEXAFS analysis was performed at the Canadian Light Source facility, which is supported by NSERC, NRC, CIHR and other government agencies.

Open Access This article is distributed under the terms of the Creative Commons Attribution 4.0 International License (http:// creativecommons.org/licenses/by/4.0/), which permits unrestricted use, distribution, and reproduction in any medium, provided you give appropriate credit to the original author(s) and the source, provide a link to the Creative Commons license, and indicate if changes were made.

\section{References}

Allison SD, Czimczik CI, Treseder KK (2008) Microbial activity and soil respiration under nitrogen addition in Alaskan boreal forest. Glob Chang Biol 14:1156-1168

Bahr A, Ellström M, Bergh J, Wallander H (2015) Nitrogen leaching and ectomycorrhizal nitrogen retention capacity in a Norway spruce forest fertilized with nitrogen and phosphorus. Plant Soil 390:323-335

Baldrian P (2006) Fungal laccases - occurrence and properties. FEMS Microbiol Rev 30:215-242

Bengtsson-Palme J, Ryberg M, Hartmann M, Branco S, Wang Z, Godhe A, De Wit P, Sánchez-García M, Ebersberger I et al (2013) Improved software detection and extraction of ITS1 and ITS2 from ribosomal ITS sequences of fungi and other eukaryotes for analysis of environmental sequencing data. Methods Ecol Evol 4:914-919

Bödeker ITM, Clemmensen KE, de Boer W, Martin F, Olson Å, Lindahl BD (2014) Ectomycorrhizal Cortinarius species participate in enzymatic oxidation of humus in northern forest ecosystems. New Phytol 203:245-256

Bouskill N, Wood TE, Baran R, Hao Z, Ye Z, Bowen BP, Lim H, Nico P, Holman H-Y et al (2016) Belowground response to drought in a tropical forest soil. II. Change in microbial function impacts carbon composition. Front Microbiol 7:323

Bugg TDH, Ahmad M, Hardiman EM, Rahmanpour R (2011) Pathways for degradation of lignin in bacteria and fungi. Nat Prod Rep 28:1883-1896

Chambers SM, Burke RM, Brooks PR, Cairney JWG (1999) Molecular and biochemical evidence for manganesedependent peroxidase activity in Tylospora fibrillosa. Mycol Res 103:1098-1102

Development Core Team R (2014) R: a language and environment for statistical computing. R Foundation for Statistical Computing, Vienna

Freedman ZB, Romanowicz KJ, Upchurch RA, Zak DR (2015) Differential responses of total and active soil microbial communities to long-term experimental $\mathrm{N}$ deposition. Soil Biol Biochem 90:275-282

Frey SD, Ollinger S, Nadelhoffer K, Bowden R, Brzostek E, Burton A, Caldwell BA, Crow S, Goodale CL et al (2014) Chronic nitrogen additions suppress decomposition and sequester soil carbon in temperate forests. Biogeochemistry 121:305-316

Gardes M, Bruns TD (1993) ITS primers with enhanced specificity for basidiomycetes - application to the identification of mycorrhizae and rusts. Mol Ecol 2:113-118

Geisseler D, Scow KM (2014) Long-term effects of mineral fertilizers on soil microorganisms - a review. Soil Biol Biochem 75:54-63

Gillespie AW, Diochon A, Ma BL, Morrison MJ, Kellman L, Walley FL, Regier TZ, Chevrier D, Dynes JJ et al (2013) Nitrogen input quality changes the biochemical composition of soil organic matter stabilized in the fine fraction: a longterm study. Biogeochemistry 117:337-350

Gillespie AW, Sanei H, Diochon A, Ellert BH, Regier TZ, Chevrier D, Dynes JJ, Tarnocai C, Gregorich EG (2014) Perennially and annually frozen soil carbon differ in their susceptibility to decomposition: analysis of subarctic earth 
hummocks by bioassay, XANES and pyrolysis. Soil Biol Biochem 68:106-116

Gillespie AW, Phillips CL, Dynes JJ, Chevrier D, Regier TZ, Peak D (2015) Chapter one - Advances in using soft X-ray spectroscopy for measurement of soil biogeochemical processes. In: Sparks DL (ed) Advances in agronomy. Academic Press, San Diego, pp 1-32

Hao X, Jiang R, Chen T (2011) Clustering 16S rRNA for OTU prediction: a method of unsupervised Bayesian clustering. Bioinformatics 27:611-618

Hartmann M, Howes CG, VanInsberghe D, Yu H, Bachar D, Christen R, Henrik Nilsson R, Hallam SJ, Mohn WW (2012) Significant and persistent impact of timber harvesting on soil microbial communities in northern coniferous forests. ISME J 6:2199-2218

Hay TN, Phillips LA, Nicholson BA, Jones MD (2015) Ectomycorrhizal community structure and function in interior spruce forests of British Columbia under long term fertilization. For Ecol Manag 350:87-95

Hemsworth GR, Taylor EJ, Kim RQ, Gregory RC, Lewis SJ, Turkenburg JP, Parkin A, Davies GJ, Walton PH (2013) The copper active site of CBM33 polysaccharide Oxygenases. J Am Chem Soc 135:6069-6077

Ihrmark K, Bödeker ITM, Cruz-Martinez K, Friberg H, Kubartova A, Schenck J, Strid Y, Stenlid J, Brandström-Durling M et al (2012) New primers to amplify the fungal ITS2 region evaluation by 454 -sequencing of artificial and natural communities. FEMS Microbiol Ecol 82:666-677

IUSS Working Group WRB (2006) World Reference Base for Soil Resources 2006. World Soil Resources Report No 103. FAO, Rome

Kjøller R, Nilsson L-O, Hansen K, Schmidt IK, Vesterdal L, Gundersen P (2012) Dramatic changes in ectomycorrhizal community composition, root tip abundance and mycelial production along a stand-scale nitrogen deposition gradient. New Phytol 194:278-286

Kögel-Knabner I (2000) Analytical approaches for characterizing soil organic matter. Org Geochem 31:609-625

Kohler A, Kuo A, Nagy LG, Morin E, Barry KW, Buscot F, Canback B, Choi C, Cichocki N et al (2015) Convergent losses of decay mechanisms and rapid turnover of symbiosis genes in mycorrhizal mutualists. Nat Genet 47:410-415

Kõljalg U, Nilsson RH, Abarenkov K, Tedersoo L, Taylor AFS, Bahram M, Bates ST, Bruns TD, Bengtsson-Palme J et al (2013) Towards a unified paradigm for sequence-based identification of fungi. Mol Ecol 22:5271-5277

Lehmann J, Solomon D, Brandes J, Fleckenstein H, Jacobson C, Thieme J (2009) Synchrotron-based near-edge X-ray spectroscopy of natural organic matter in soils and sediments. In: Senesi N, Xing B, Huang PM (eds) Biophysico-chemical processes involving natural nonliving organic matter in environmental systems. Wiley, Hoboken, pp 729-781

Leinweber P, Kruse J, Walley FL, Gillespie A, Eckhardt K-U, Blyth RIR, Regier T (2007) Nitrogen K-edge XANES - an overview of reference compounds used to identify 'unknown' organic nitrogen in environmental samples. J Synchrotron Radiat 14:500-511

Leinweber P, Jandl G, Eckhardt KU, Kruse J, Walley FL, Khan MJ, Blyth RIR, Regier T (2010) Nitrogen speciation in fine and coarse clay fractions of a Cryoboroll - new evidence from pyrolysis-mass spectrometry and nitrogen K-edge XANES. Can J Soil Sci 90:309-318

Leinweber P, Kruse J, Baum C, Arcand M, Knight JD, Farrell R, Eckhardt K-U, Kiersch K, Jandl G (2013) Chapter two Advances in understanding organic nitrogen chemistry in soils using state-of-the-art analytical techniques. In: Sparks DL (ed) Advances in agronomy. Academic Press, San Diego, pp 83-151

Lindahl BD, Tunlid A (2015) Ectomycorrhizal fungi - potential organic matter decomposers, yet not saprotrophs. New Phytol 205:1443-1447

Lindahl BD, Ihrmark K, Boberg J, Trumbore SE, Högberg P, Stenlid J, Finlay RD (2007) Spatial separation of litter decomposition and mycorrhizal nitrogen uptake in a boreal forest. New Phytol 173:611-620

Martínez AT, Rencoret J, Nieto L, Jiménez-Barbero J, Gutiérrez A, del Río JC (2011) Selective lignin and polysaccharide removal in natural fungal decay of wood as evidenced by in situ structural analyses. Environ Microbiol 13:96-107

Marzluf GA (1997) Genetic regulation of nitrogen metabolism in the fungi. Microbiol Mol Biol Rev 61:17-32

Mehta D, Satyanarayana T (2013) Diversity of hot environments and thermophilic microbes. In: Satyanarayana T, Littlechild J, Kawarabayasi Y (eds) Thermophilic microbes in environmental and industrial biotechnology. Springer, Heidelberg, pp 3-60

Morrison EW, Frey SD, Sadowsky JJ, van Diepen LTA, Thomas WK, Pringle A (2016) Chronic nitrogen additions fundamentally restructure the soil fungal community in a temperate forest. Fungal Ecol 23:48-57

Oksanen J, Blanchet FG, Kindt R, Legendre P, Minchin PR, O'hara RB, Simpson GL, Solymos P, Stevens MHH et al (2016) Vegan: community ecology package. R package version 2.0-2.3-4

Phillips LA, Ward V, Jones MD (2014) Ectomycorrhizal fungi contribute to soil organic matter cycling in sub-boreal forests. ISME J 8:699-713

Purton K, Pennock D, Leinweber P, Walley F (2015) Will changes in climate and land use affect soil organic matter composition? Evidence from an ecotonal climosequence. Geoderma 253-254:4860

Rinkes ZL, Bertrand I, Amin BAZ, Grandy AS, Wickings K, Weintraub MN (2016) Nitrogen alters microbial enzyme dynamics but not lignin chemistry during maize decomposition. Biogeochemistry 128:171-186

Saison C, Degrange V, Oliver R, Millard P, Commeaux C, Montange D, Le Roux X (2006) Alteration and resilience of the soil microbial community following compost amendment: effects of compost level and compost-borne microbial community. Environ Microbiol 8:247-257

Schloss PD, Westcott SL, Ryabin T, Hall JR, Hartmann M, Hollister EB, Lesniewski RA, Oakley BB, Parks DH et al (2009) Introducing mothur: open-source, platform-independent, community-supported software for describing and comparing microbial communities. Appl Environ Microbiol 75:7537-7541

Schulten HR, Schnitzer M (1997) The chemistry of soil organic nitrogen: a review. Biol Fertil Soils 26:1-15

Shah F, Nicolás C, Bentzer J, Ellström M, Smits M, Rineau F, Canbäck B, Floudas D, Carleer R et al (2016) Ectomycorrhizal fungi decompose soil organic matter using oxidative mechanisms adapted from saprotrophic ancestors. New Phytol 209:1705-1719 
Söderström BE (1979) Seasonal fluctuations of active fungal biomass in horizons of a podzolized pine-forest soil in central Sweden. Soil Biol Biochem 11:149-154

Solomon D, Lehmann J, Kinyangi J, Liang B, Schäfer T (2005) Carbon K-edge NEXAFS and FTIR-ATR spectroscopic investigation of organic carbon speciation in soils. Soil Sci Soc Am J 69:107-119

Solomon D, Lehmann J, Kinyangi J, Liang B, Heymann K, Dathe L, Hanley K, Wirick S, Jacobsen C (2009) Carbon (1s) NEXAFS spectroscopy of Biogeochemically relevant reference organic compounds. Soil Sci Soc Am J 73:1817-1830

Solomon D, Lehmann J, Harden J, Wang J, Kinyangi J, Heymann K, Karunakaran C, Lu Y, Wirick S et al (2012) Micro- and nano-environments of carbon sequestration: multi-element STXM-NEXAFS spectromicroscopy assessment of microbial carbon and mineral associations. Chem Geol 329:53-73

Talbot JM, Treseder KK (2010) Controls over mycorrhizal uptake of organic nitrogen. Pedobiologia 53:169-179

Taylor AFS, Martin F, Read DJ (2000) Fungal diversity in ectomycorrhizal communities of Norway spruce [Picea abies (L.) Karst.] and beech (Fagus sylvatica L.) along north-south transects in Europe. In: Schulze E-D (ed) Carbon and nitrogen cycling in European Forest ecosystems. Springer, Berlin, pp 343-365
Tedersoo L, May TW, Smith ME (2010) Ectomycorrhizal lifestyle in fungi: global diversity, distribution, and evolution of phylogenetic lineages. Mycorrhiza 20:217-263

Wallander H, Nilsson LO, Hagerberg D, Bååth E (2001) Estimation of the biomass and seasonal growth of external mycelium of ectomycorrhizal fungi in the field. New Phytol 151:753-760

Wallander H, Nilsson LO, Hagerberg D, Rosengren U (2003) Direct estimates of C:N ratios of ectomycorrhizal mycelia collected from Norway spruce forest soils. Soil Biol Biochem 35:997-999

Wallander H, Johansson U, Sterkenburg E, Brandström Durling M, Lindahl BD (2010) Production of ectomycorrhizal mycelium peaks during canopy closure in Norway spruce forests. New Phytol 187:1124-1134

Wallander H, Ekblad A, Bergh J (2011) Growth and carbon sequestration by ectomycorrhizal fungi in intensively fertilized Norway spruce forests. For Ecol Manag 262:999-1007

Wojdyr M (2010) Fityk: a general-purpose peak fitting program. J Appl Crystallogr 43:1126-1128

$\mathrm{Wu}$ TH (2011) Can ectomycorrhizal fungi circumvent the nitrogen mineralization for plant nutrition in temperate forest ecosystems? Soil Biol Biochem 43:1109-1117 